\title{
Giant Upper Eyelid Sehwannoma with Total Upper Lid Reconstruction
}

\section{Salil Kumar Mandal' , Aparna Mandal' ${ }^{2}$ Biplab Kumar Biswas ${ }^{3}$}

JCR

From the Department of Ophthalmology', Regional Institute of Ophthalmology, Medical College \& Hospital, Kolkata; Department of Physiology², College of Medicine \& Sagore Dutta Hospital, Kolkata; Department of Pathology ${ }^{3}$, Bankura Sammilani Medical College, Bankura, West Bengal, India.

Abstract:

Schwannoma is a slowly growing, asymptomatic, benign neoplasm. It arises from neuroectodermic origin of Schwann cells present in the myelinated peripheral nerve sheath. However, its location in eyelid is rare. A 72 years old woman was referred to us with one and half years history of painless, progressively increasing size of large tumour mass originating from left upper lid. It was horizontally situated, approximately $4 \mathrm{~cm} / 3$ $\mathrm{mm}$ in both horizontal and vertical dimension. For the last one year, it was growing rapidly. Patient was unable to open his eyelid and had associated ptosis. Various differential diagnosis considered were fibroma, epidermal inclusion cyst, solitary neurilemmoma. We planned complete excision biopsy of the mass with 3 $\mathrm{mm}$ clear margin followed by histopathological examination. Principal of Cutler Beard procedure were applied with some modification for complete excision of the mass followed by total upper lid reconstruction. Mass was succesfully removed and histopathology report shows eyelid schwannoma with strong reactivity to S100 protein by immunohistochemistry. No recurrence was noted at one year followup.

Key words: Eyelids, Neurofibroma, Neurilemmoma, Blepharoptosis, Cysts, Immunohistochemistry.

\section{Introduction}

Schwannoma in the eyelid is rare benign neoplasm. It has neuroectodermic origin of Schwann cells present in the myelinated peripheral nerve sheath. Most commonly seen in head and neck region and it preferentially involves spinal nerve roots, sympathetic, cervical, and vagus nerves. Rarely, it may be present in the orbit, lids, conjunctiva, sclera and uveal tract. It may be associated with generalised neurofibomatosis but solitary presentation of this tumour may not have any association [1-4].

\section{Case Report}

A 72 year old woman was referred to us with one and half years history of painless, progressively increasing size of mass over left upper eye lid [Fig. 1]. It was horizontally disposed, approximately $4 \mathrm{~cm} / 3 \mathrm{~mm}$ in horizontal and vertical dimension. According to the patient this tumour first appeared

Corresponding Author: Dr. Salil Kumar Mandal

Email: salil_dum@live.com

Received: June 15, 2014 | Accepted: July 5, 2014 | Published Online: July 30, 2014

This is an Open Access article distributed under the terms of the Creative Commons Attribution License (creativecommons.org/licenses/by/3.0)

Conflict of interest: None declared | Source of funding: Nil | DOl: http://dx.doi.org/10.17659/01.2014.0070 
as upper lid nodule. But for the last one year, it was growing rapidly and she was unable to open the eyelid. Patient developed ptosis and difficulties in vision due to large tumour and weight of the mass. Examination revealed large swelling arising from the upper lid, involving the entire length of the lid. Surface was smooth, overlying skin stretched, surface blood vessels were engorged and torturous, with no colour or temperature changes, no expansible impulse on coughing and on auscultation no bruit was heard. Texture of the tumour mass was firm and solid. Underlying cornea, anterior chamber, lens and fundus were within normal limit. Patient had good useful vision. There was no evidence of generalised neurofibromatosis or lymphadenopathy. Patient was known hypertensive with past history of ishemic heart disease. X-ray, ultrasound and CT orbit revealed localised solid mass. Routine blood examination were within normal limit. Our differential diagnosis were fibroma, epidermal
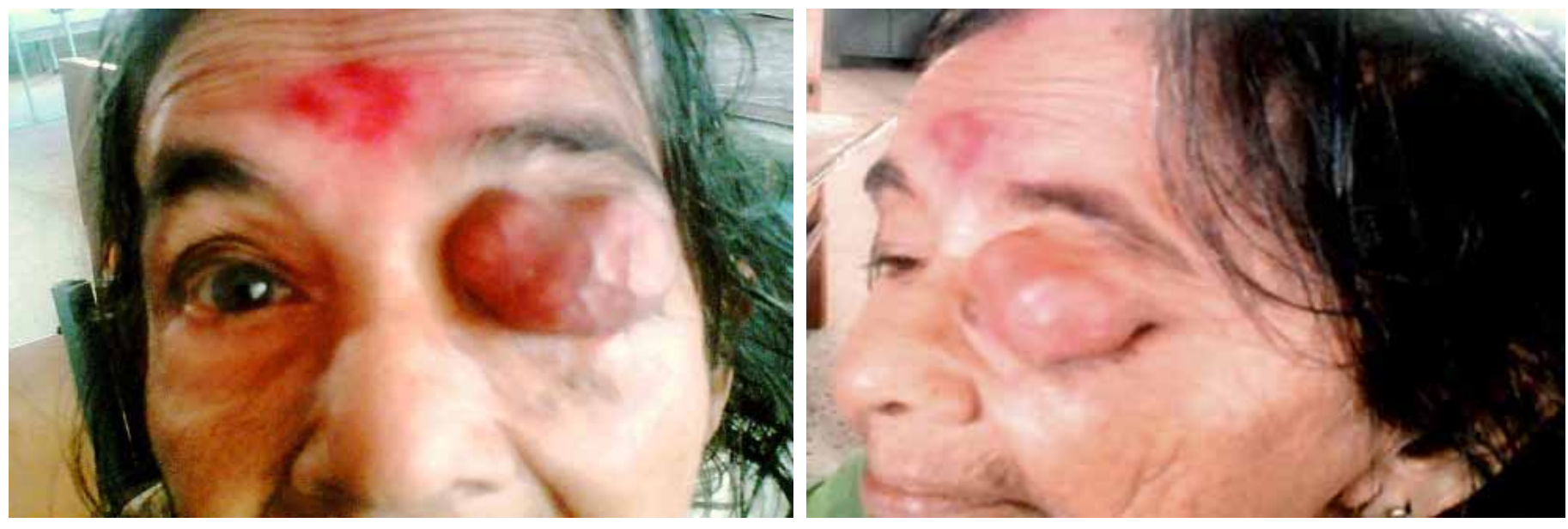

Fig.1: Left upper lid Schwamanoma: AP \& Lateral view.
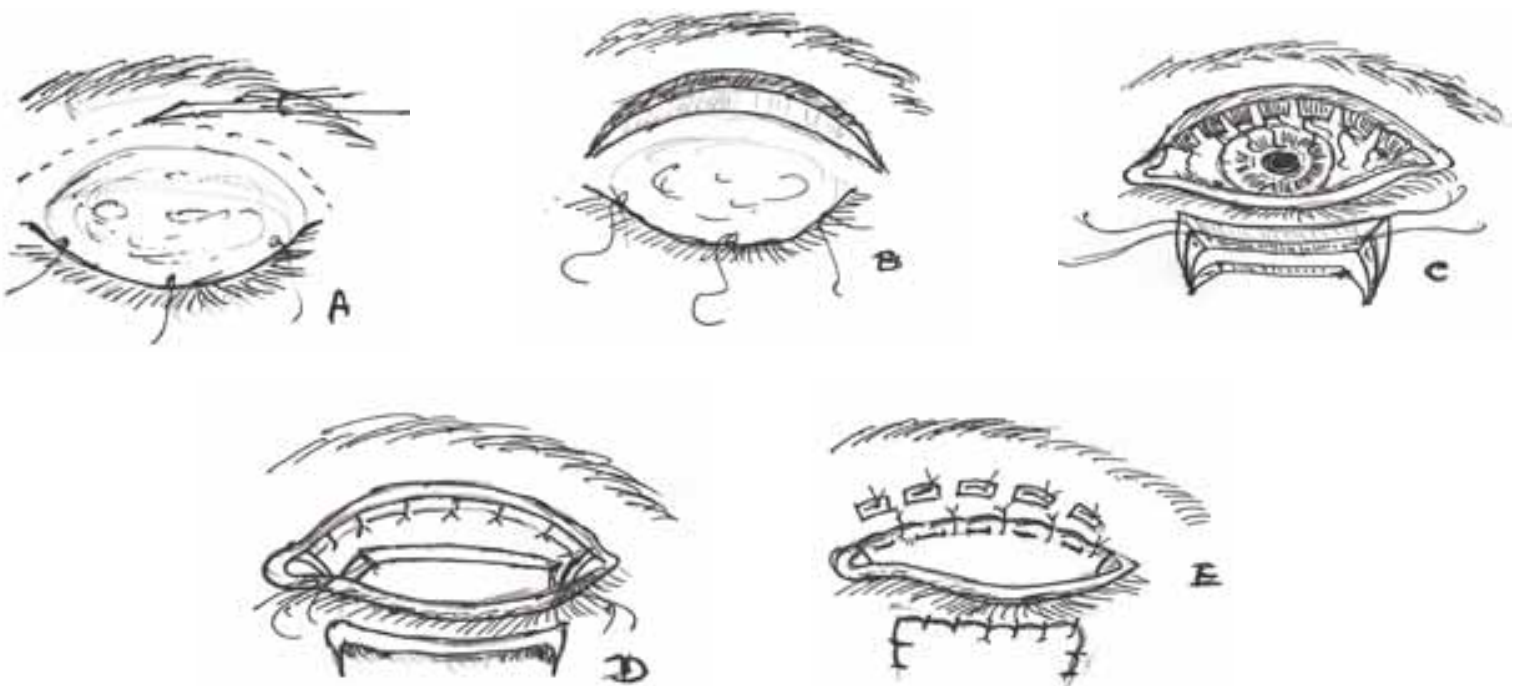

Schematic Diagram: Stages of modified Cutler Beard procedure for upper lid reconstruction. 

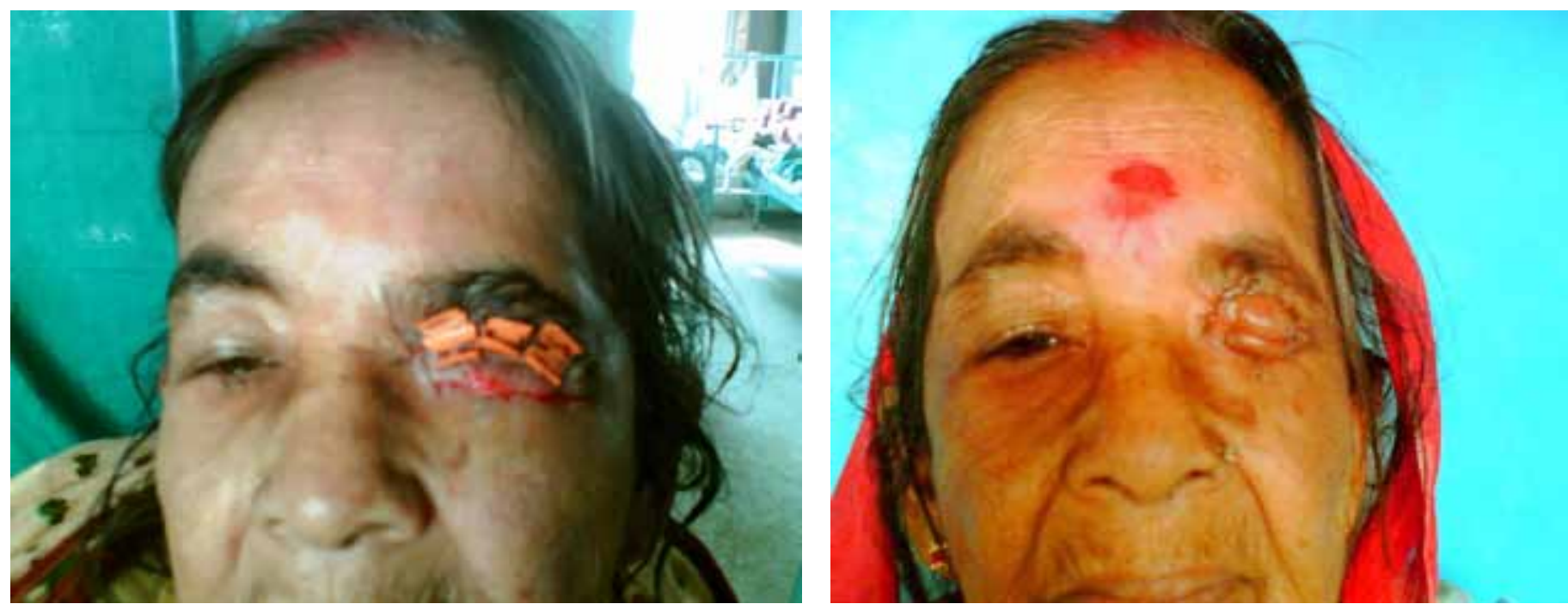

Fig.2: Immediately after $3^{\text {rd }}$ post operative day and after removal of all sutures in $2^{\text {nd }}$ month.
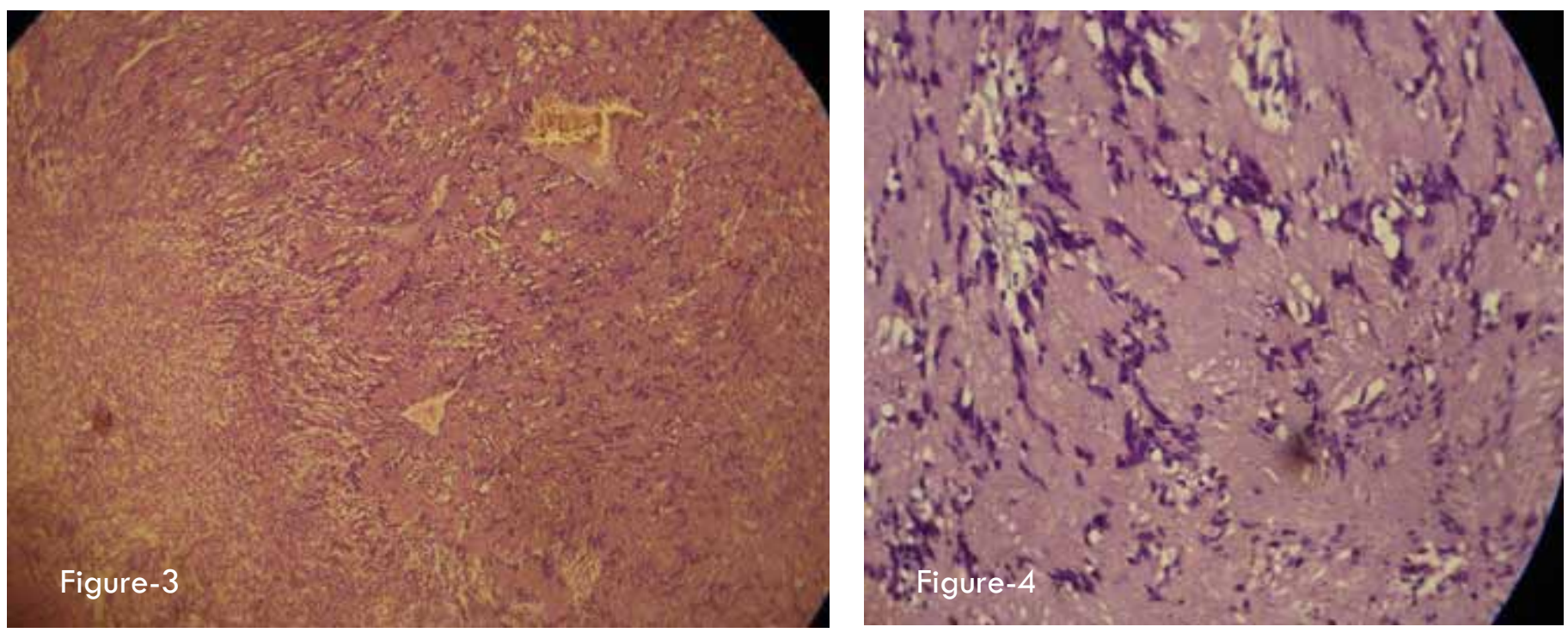

Fig.3(40X,H/E) \& Fig.4(400X,H/E): Schwannoma with alternating Antoni A and Antoni $B$ areas.

inclusion cyst, solitary neurilemmoma. The plan was wide excision with $3 \mathrm{~mm}$ clear margin, with removal of tumour mass and reconstruction of the upper lid to prevent ptosis postoperatively, achieve acceptable cosmesis and useful vision to patient followed by histopathological examination. Procedure was done under general anaesthesia with blood transfusion facilities and with high risk special consent.
Following the principal of two stage Cutler Beard procedure for upper lid reconstruction with modification, elliptical curved incision was made $3 \mathrm{~mm}$ away from the solid mass involving entire length of upper lid. Skin, sub-cutaneous tissue, strip of orbicularis were cut in a same plane then orbital septum, LPS and conjunctiva secured by interrupted stay suture with 5-0 polyglactin. Parallel full 
thickness incision was made horizontally $3 \mathrm{~mm}$ below the lower lid border, then two vertical full thickness incision made at the edge of the previous incision. Tissue was mobilized from the lower lid towards the upper lid. This full thickness flap splits into skin, muscle and orbital septum, conjunctiva. Upper lid orbital septum, LPS, conjunctiva joined with the lower lid orbital septum and conjunctiva with interrupted 5-0 polyglactin suture. Skin muscle of upper lid joined with the lower lid skin muscle with interrupted 5-0 black silk over rubber plegates to prevent skin necrosis in suture line under tension. Interrupted skin suture made for good wound closure. Immediately after $3^{\text {rd }}$ post operative day wound was closed over rubber plegets to prevent wound necrosis and wound was healthy after removal of all sutures at $2^{\text {nd }}$ month, however, patient developed ptosis.

\section{Discussion}

Schwannoma is a benign neoplasm slowly growing in nature, asymptomatic. It's upper lid entity is rare. Schwann cell tumors generally arise from peripheral or cranial nerves. Schwannomas are rare in ophthalmology, although they have been reported in relation to the orbit ( $1 \%$ of orbital tumors). Eyelid schwannomas are extremely uncommon $[1,3]$.

There are several clinico-pathologic variants of schwannoma, including conventional schwannoma, cellular schwannoma, and melanotic schwannoma. Microscopically, they may demonstrate a biphasic pattern with areas of highly cellular (Antoni type A) and myxoid matrix (Antoni type B). The most important feature in it's diagnosis remains the strong reactivity to $S 100$ protein by immunohistochemistry, particularly in Antoni type A [4-6]. Eyelid schwannomas have been confused with epidermal inclusion cysts, solitary neurofibroma or giant chalazion. Their management is complete excision with clear margins to establish the histopathologic diagnosis and prevent recurrence. Incomplete removal is associated with eventual recurrence and more aggressive behaviour. The female to male ratio was $3: 2[2,7,8]$. Our case was not associated with neurofibromatosis. In this case the mass was located on the entire upper eyelid and involved the edge of the upper eyelid. This location has not been described previously in adults, and the tumour probably arise from branches of the supraorbital nerve $[6,8]$.

In this case, our plan was to completely excise the mass followed by histopathological examination. We applied the principal of Cutler-Beard procedure with modification for complete excision of the mass followed by total upper lid reconstruction. It successfully removed the mass. Histopathology report shows eyelid schwannoma. There is strong reactivity to $\mathrm{S} 100$ protein by immunohistochemistry, particularly in Antoni type A. With one year follow up no recurrence was noted.

After operation patient is highly satisfied for cosmetic and some degree of vision though the patient is having ptosis. She is planned for tarsofrontalis sling with silicon rod for ptosis correction later on.

\section{References}

1. Baijal GC, Garg SK, Kanhere S, Monga S. Schwannoma of the eye-lid. Indian J Ophthalmol 1980;28:155-156.

2. Scheithaver BW, Woodruff JM, Erlandson RA. Tumors of the peripheral nervous system. In: Rosai J, Sobin LH (eds) Atlas of Tumor Pathology. Third series, fasc. 24, Armed Forces Institute Pathology: Washington, D.C.,1999;105-176.

3. Butt Z, Ironside JW. Superficial epithelioid schwannoma presenting as a subcutaneous upper eyelid mass. $\mathrm{Br} J$ Ophthalmol 1994;78:586588.

4. Shields JA, Guibor P. Neurilemoma of the eyelid resembling a recurrent chalazion. Arch Ophthalmol 1984;102:1650. 
5. Shields JA, Kiratli H, Shields CL, Eagle RC Jr, Luo S. Schwannoma of the eyelid in a child. J Pediatr Ophthalmol Strabismus 1994;31:332333.

6. Siddiqui MA, Leslie T, Scott C, MacKenzie J. Eyelid schwannoma in a male adult. Clin
Experiment Ophthalmol 2005;33:412-413.

7. Reeh MJ. Treatment of Lid and Epibulbar Tumors. Springfield, IL: Thomas Publishers; 1963.

8. Rootman J, Goldberg C, Robertson W. Primary orbital schwannomas. Br J Ophthalmol 1982;66:194-204. 